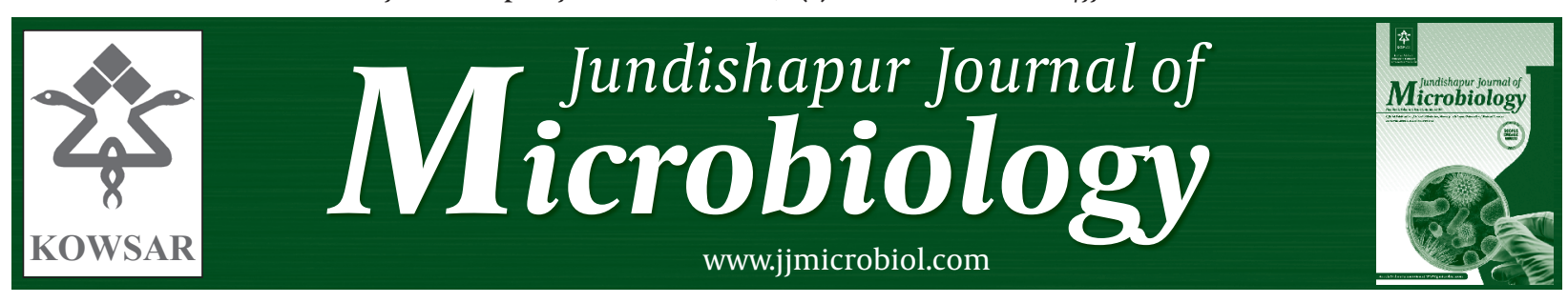

\title{
Antimicrobial Resistance in Salmonella enterica Isolated From Pork, Chicken, and Vegetables in Southern Thailand
}

\author{
Monthon Lertworapreecha ${ }^{1^{*}}$, Suparat Sutthimusik ${ }^{1}$, Kumchai Tontikapong ${ }^{2}$ \\ ${ }^{1}$ Department of Biology, Faculty of Science, Thaksin University (Phattalung Campus), Paphayom, Phatthalung, Thailand \\ ${ }^{2}$ Department of Animal Production Technology, Faculty of Technology and Community Development, Thaksin University (Phatthalung Campus), Papha- \\ yom, Phatthalung, Thailand
}

\begin{tabular}{l}
\hline A R T I C L E I N F O \\
\hline Article type: \\
Original Article \\
\hline Article history: \\
Received: 31 Jan 2012 \\
Revised: 11 Apr 2012 \\
Accepted: 29 Apr 2012 \\
\hline
\end{tabular}

\begin{abstract}
A B S T R A C T
Background: Salmonella is a common causative agent of food-borne illness in humans. Infection by this pathogen is usually due to ingestion of contaminated insufficiently cooked foods. Despite the fact that several studies of the prevalence and antimicrobial resistance of Salmonella have been conducted in Thailand, there is limited data available concerning the more rural areas of the country.

objectives: This study aimed to investigate the prevalence and antimicrobial resistance profiles of Salmonella in meat and vegetable samples taken from Phatthalung Province, Thailand. Materials and Methods: Pork and chicken meat and fresh vegetable samples were randomly selected from retail markets in Phatthalung Province. Salmonella isolation and identification were performed on the same day of sample collection. Serovar typing was performed by slide agglutination according to The Kauffman and White scheme. Antimicrobial susceptibility testing was performed by disc diffusion method, and antimicrobial susceptibility patterns were analyzed by the WHONET 5 program.

Results: The prevalence of Salmonella in retail pork, chicken meat, and fresh vegetables were $82 \%(34 / 41), 67.5 \%(27 / 40)$, and $46 \%$ (37/80), respectively. The Salmonella isolated from pork, and vegetables were most resistant to tetracycline (77 and 33\%) while the Salmonella isolated from chicken meat was most resistant to streptomycin (92\%). Thirty-one samples (68\%) isolated from pork and thirty-two samples (84\%) isolated from chicken meat were of MDR strains. whereas only 7 samples (29\%) isolated from vegetables exhibited resistance to two or more antimicrobial drugs.

Conclusions: These results show that retail meat and vegetables can serve as a reservoir of multiple antimicrobial resistant Salmonella and can probably be a potential route of transmission of these pathogens into human population.
\end{abstract}

Published by Kowsar Corp, 2013. cc 3.0.

- Implication for health policy/practice/research/medical education:

This study provides useful information on surveillance of antimicrobial resistance in Salmonella and monitoring for preventing in food-borne disease at Phatthalung, Southern of Thailand. We have observed that retail meat (pork and chicken meat) and fresh vegetables can serve as a source for MDR strains of Salmonella that may affect to consumer health.

- Please cite this paper as:

Lertworapreecha M, Sutthimusik S, Tontikapong K. Antimicrobial Resistance in Salmonella enterica Isolated From Pork, Chicken, and Vegetables in Southern Thailand. JundishapurJ Microbiol. 2013;6(1):36-41. DOI: 10.5812/jjm.4312

* Corresponding author: Monthon Lertworapreecha, Department of Biology, Faculty of Science, Thaksin University, (Phattalung Campus), 222 Paphayom, Phatthalung, 93110, Thailand. Tel:+66-74693992, Fax:+66-74693992, E-mail: worapreecha@gmail.com

DOI: $10.5812 / j \mathrm{jm} .4312$

(C) 2013 Ahvaz Jundishapur University of Medical Sciences; Published by Kowsar Corp.

This is an Open Access article distributed under the terms of the Creative Commons Attribution License (http://creativecommons.org/licenses/by/3.0), which permits unrestricted use, distribution, and reproduction in any medium, provided the original work is properly cited. 


\section{Background}

Salmonella is a common causative agent of food-borne illnesses in humans and a growing worldwide public health problem $(1,2)$. In Thailand, epidemiological reports indicate that Salmonella is encountered as the most common cause of diarrhea, which is widespread in all parts of the country (3). Salmonella is able to colonize in animal intestinal tracts, mainly swine and chicken, and shed in the feces (4-6). Therefore, Salmonella contamination in pork or chicken is unavoidable in the human food supply chain. Additionally, probably due to the use of manure fertilizer in their cultivation, Salmonella contamination can also be found in various types of vegetables (7). The illness is usually transmitted through food contaminated by feces. Furthermore, the resistance of Salmonella to a range of antimicrobial agents has become a serious global concern in public health.

An increasing number of antimicrobial resistant Salmonella has been reported in both developed and developing countries. Recently, a study in Denmark reported that the frequency of quinolone-resistant S. Enteritidis has increased from $0.8 \%$ in 1995 to $8.5 \%$ in 2000 (8). According to an investigation in England and Wales from 2000 to 2004, antimicrobial resistant S. Enteritidis has increased from $19 \%$ in 2000 to $35 \%$ in 2004 , and antimicrobial resistant S. Typhimurium has increased from $82 \%$ in 2000 to $90 \%$ in 2002 (9). Moreover, a consequence of multidrug resistant (MDR) Salmonella infection has been previously reported, in which patients who were infected by MDR strain of S. typhimurium had an approximately 10 times higher mortality rate than general population (10). To ensure adequate consumer protection, especially in urban areas, several methods for decreasing contamination have been implemented in animal production and slaughtering system. In the countryside of Thailand, most animal and vegetable production is supplied for local consumption and therefore, the issue of food safety and Salmonella contamination in food, animal products, and vegetables may receive insufficient attention in these areas.

\section{Objectives}

To reduce contamination and illness caused by Salmonella infection, the prevalence of Salmonella contamination and antimicrobial susceptibility data in meat and vegetable products must be monitored. Hence, the aims of this study were to investigate the prevalence and antimicrobial resistance profiles of Salmonella found in contaminated pork, chicken meat, and vegetables in Phatthalung Province, Southern Thailand.

\section{Materials and Methods}

\subsection{Samples}

Forty-one samples of pork, 40 samples of chicken meat, and 80 samples of fresh vegetables were randomly selected from retail markets in Phatthalung Province during the period of October to December 2010. Samples were kept in separate sterile plastic bags, stored in cool boxes, and transported to laboratory on the same day of sample collection for isolation and identification of Salmonella.

\subsection{Salmonella Isolation and Identification}

Approximately 25 Grams of surface area of pork, chicken meat, and fresh vegetables were cut into small pieces by sterile scissors before being added to a stomach bag containing $225 \mathrm{~mL}$ of buffered peptone water (BPW) and incubated at $37^{\circ} \mathrm{C}$ for 24 hours. Subsequently, $100 \mu \mathrm{L}$ and $5 \mathrm{~mL}$ of pre-enriched cultures were transferred to Modified Semi-solid Rappaport-Vassiliadis (MSRV) medium (Criterion, U.S.A) and Rappaport Vassiliadis (RV) broth, respectively and incubated at $42{ }^{\circ} \mathrm{C}$ for 24 hours. Then, one loopful from each of the enriched broths were streaked onto Xylose Lysine Desoxycholate (XLD) agar (Himedia, India) plates and incubated at $37{ }^{\circ} \mathrm{C}$ for 18 to 24 hours. At least 5 single typical colonies of Salmonella were randomly picked up and stabbed into Triple Sugar Iron (TSI) agar (Criterion, U.S.A) and Lysine Indole Motile (LIM) medium (Himedia, India) and incubated at $37^{\circ} \mathrm{C}$ for 18 to 24 hours. Typical characteristics of Salmonella exhibited on TSI agar were selected to subculture on Tryptic Soy (TSA) agar (Himedia, India). Suspected Salmonella colonies were confirmed by biochemical reactions (motility, indole production, lysine decarboxylase and carbohydrate fermentation) and slide agglutination with Salmonella $\mathrm{O}$ antigen antiserum. Final confirmation test was obtained through Salmonella serotyping performed by slide agglutination with $\mathrm{O}$ and $\mathrm{H}$ Salmonella antisera (S\&A reagent, Thailand).

\subsection{Antimicrobial Susceptibility Testing}

All isolates were tested for 10 antimicrobial drugs (oxoids); tetracycline $(30 \mu \mathrm{g})$, ciprofloxacin $(5 \mu \mathrm{g})$, chloramphenicol $(30 \mu \mathrm{g})$, ampicillin $(10 \mu \mathrm{g})$, norfloxacin (10 $\mu \mathrm{g})$, nalidixic acid (30 $\mu \mathrm{g})$, streptomycin $(10 \mu \mathrm{g})$, trimethoprim/sulfamethoxazole (25 $\mu \mathrm{g})$, cephalothin (30 $\mu \mathrm{g})$, and gentamicin $(10 \mu \mathrm{g})$. Susceptibility testing was performed according to recommendations of Clinical and Laboratory Standards Institute (CLSI) (11). To standardize bacterial suspension (in $0.8 \% \mathrm{NaCl}$ ), the density of suspension was adjusted to 0.5 McFarland and spread over the entire surface of Mueller Hinton agar (MHA) plates using a sterile cotton swab. Antimicrobial discs were placed on the agar surface followed by incubation of the plates at $37^{\circ} \mathrm{C}$ for 24 hours. Inhibition zones were measured by Venire Caliper and interpreted accordingly by CLSI recommendations. The results were analyzed by WHONET 5 program. 


\section{Results}

\subsection{Prevalence of Salmonella Serotypes in Samples}

Of 161 samples, 41 samples were prepared from retail pork, 40 samples from chicken meat, and 80 samples from fresh vegetables. The prevalence of Salmonella contamination in retail pork, chicken meat, and fresh vegetables were $82 \%$ (34/41), 67.5\% (27/40), and 46\% (37/80), respectively. Among all positive samples, 45 isolates, 38 isolates, and 29 isolates of Salmonella were segregated from pork, chicken meat, and vegetables, respectively. The most predominant serotypes isolated from pork, chicken meat, and fresh vegetables were S. Rissen (28.8\%), S. albany (44.7\%), and S. Typhimurium (33.3\%), respectively. Frequency of isolated serotypes from pork, chicken meat, and vegetables is presented in Table 1.

\begin{tabular}{|c|c|c|c|}
\hline & $\begin{array}{l}\text { Pork, } \\
\text { No. (\%) }\end{array}$ & $\begin{array}{l}\text { Chicken Meat, } \\
\text { No. }(\%)\end{array}$ & $\begin{array}{l}\text { Vegetables, } \\
\text { No. (\%) }\end{array}$ \\
\hline Rissen & $13(28.8)$ & $3(7.8)$ & \\
\hline Anatum & $3(6.6)$ & & \\
\hline Weltevreden & $12(26.6)$ & $1(2.6)$ & $6(20)$ \\
\hline Typhimurium & $2(4.4)$ & $7(18.4)$ & $10(33.3)$ \\
\hline Give & $4(8.8)$ & $5(13.15)$ & \\
\hline Dirby & $1(2.2)$ & & \\
\hline Kentucky & $1(2.2)$ & $1(2.6)$ & \\
\hline Bredeney & $9(20)$ & & \\
\hline Albany & & $17(44.7)$ & \\
\hline Hvittingfoss & & $1(2.6)$ & $7(23.3)$ \\
\hline Kalamu & & $3(7.8)$ & \\
\hline Eastbourne & & & $3(10)$ \\
\hline Paratyphi B & & & $2(6.6)$ \\
\hline Kotu & & & $1(3.3)$ \\
\hline Total & 45 & 38 & 29 \\
\hline
\end{tabular}

\subsection{Antimicrobial Susceptibility Testing and Multi Drug} Resistance Profiles

Antimicrobial susceptibility testing was performed for all isolates. The results revealed that Salmonella isolated from pork were mostly resistant to tetracycline (77\%), streptomycin (71\%), and ampicillin (51\%). For Salmonella isolated from chicken samples, highest resistance was observed against streptomycin (92\%) followed by nalidixic acid (76\%), ampicillin (68\%), and chloramphenicol (68\%). Despite of meat samples, fewer antimicrobial resistant Salmonella were observed in vegetable samples, mostly resistant to tetracycline (33\%) followed by ampicillin (20\%) and streptomycin (20\%). All antimicrobial resistance profiles in Salmonella isolated from each sample are presented in Table 2.

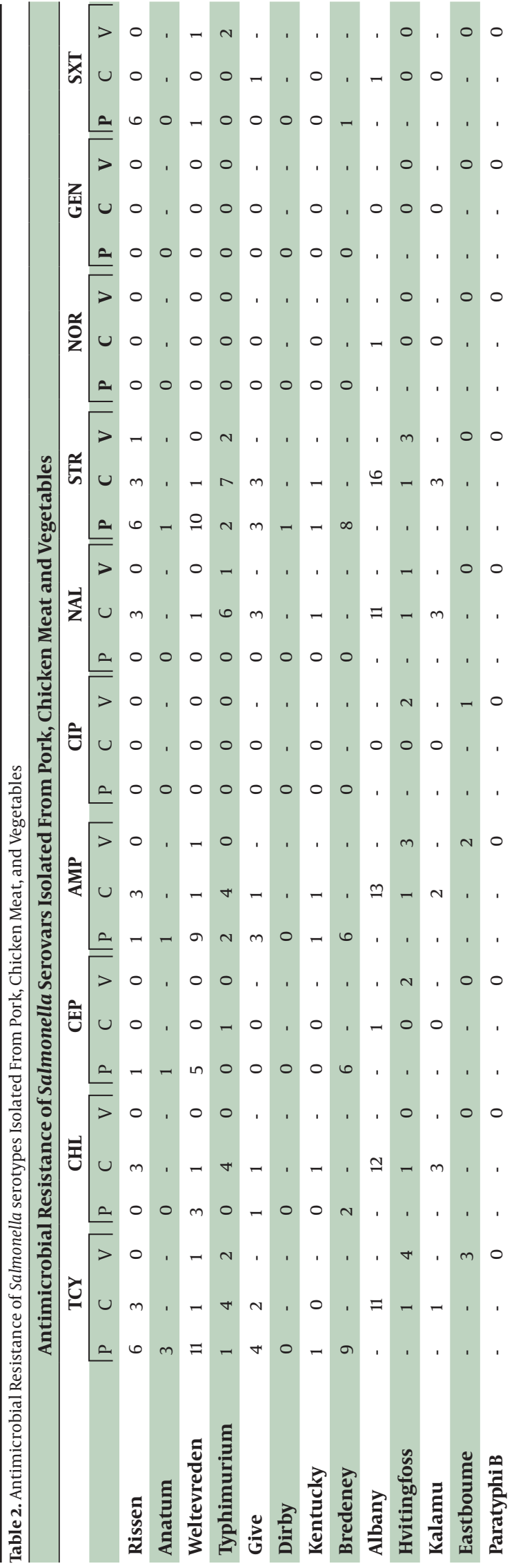




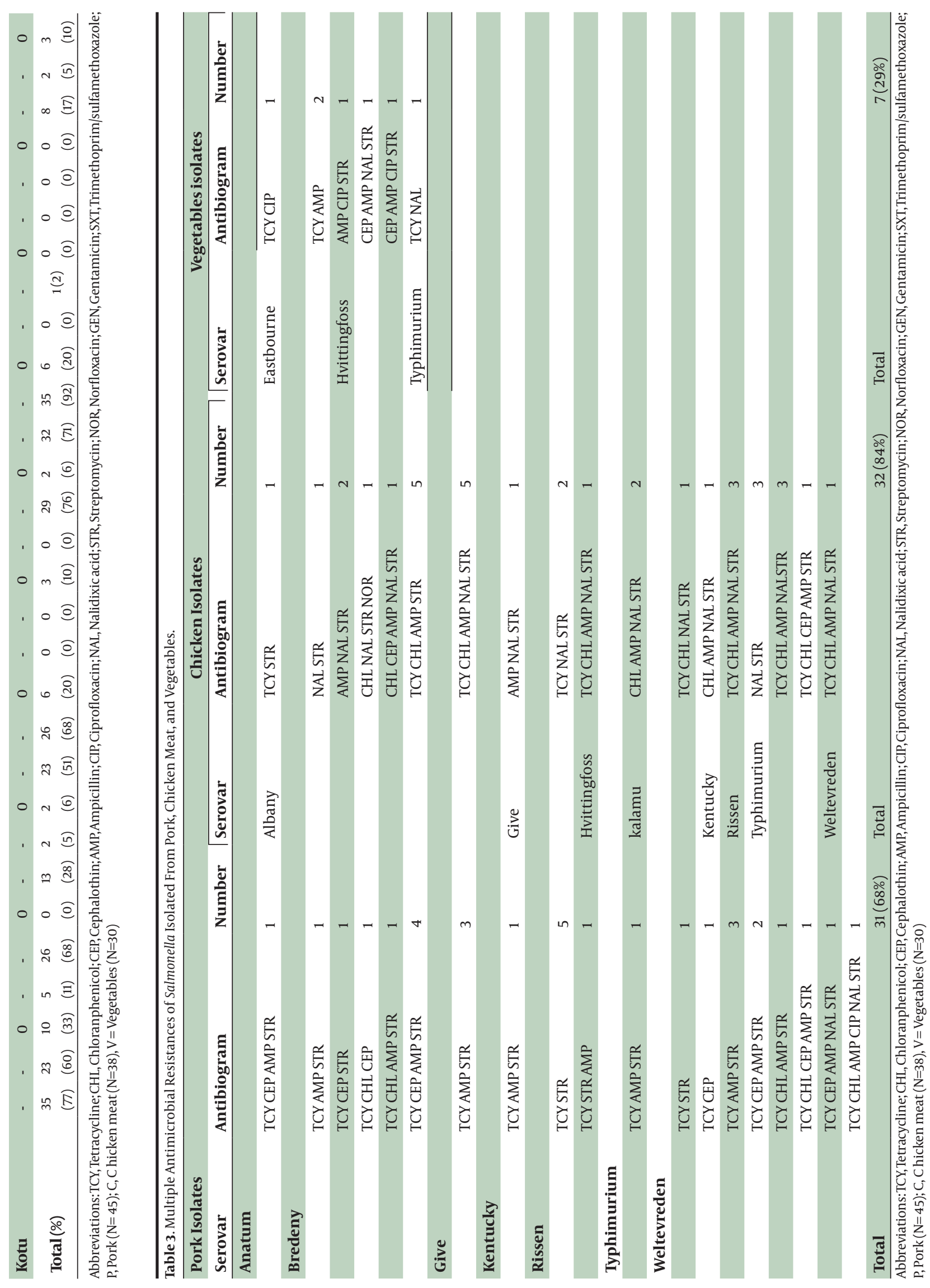


In addition, all Salmonella isolated were analyzed for multiple drugs resistance profiles, and it was revealed that in thirty-one pork samples (68\%) several isolates were of MDR strains, mostly S. weltevreden. Thirty-two samples (84\%) isolated from chicken were of the MDR strains, mostly $S$. albany. However, only 7 samples (29\%) isolated from vegetables exhibited resistance to two or more antimicrobial drugs. Distribution of serotypes and multiple antimicrobial resistance patterns pertaining to pork, chicken meat, and vegetables are presented in Table 3.

\section{Discussion}

The problems attributed to Salmonella infection have increased significantly, in terms of both incidence and severity. Furthermore, an increase of antimicrobial resistance in this pathogen makes the treatment of infection more difficult that probably results in death. Therefore, epidemiological information and monitoring systems are necessary to control Salmonella infection in public health sector. In this study, we observed prevalence and antimicrobial susceptibility patterns of Salmonella isolated from pork, chicken meat, and vegetables. The study showed that the retail pork was highly contaminated by Salmonella, followed by chicken meat and fresh vegetables. These products, according to many reports, are the resources of Salmonella contamination $(1,2,12,13)$.

Serotyping of Salmonella isolated from pork indicated that $S$. Rissen was the most predominant serotype followed by S. weltevreden, whereas S. albany and S. typhimurium were the most predominant serotyping found in chicken meat and vegetables, respectively. Our results are inconsistent with previous findings in Thailand which indicated that S. albany and S. give were predominantly found in swine and chicken farms, respectively (14). The inconsistency in observed serotypes may be attributed to different areas studied and sample types used in this investigation. Although serotyping were not the same as in other studies, those that were observed were included within 25 most common serotyping isolated from human and other sources in Thailand (15).

High contamination of Salmonella implies that hygienic performance in carcass production processes, especially in slaughters of Phattalung Province area, probably are insufficiently attended. Antimicrobial susceptibility testing revealed high resistance rates against several antimicrobial drugs used in both medical and agricultural fields. Salmonella isolated from pork samples were commonly resistant to tetracycline, ampicillin, and streptomycin, as was in those isolated from chicken, which were additionally resistant to nalidixic acid. High resistance to those antimicrobial drugs were consistent to previous observations from various countries (16-18), which implies that the wide consumption of such antimicrobials as feed additives in livestocks contributes to emergence and dissemination of resistance in Salmonella. In addi- tion, it had also been reported the sub-therapeutic doses of antimicrobial drugs in animal husbandry as a responsible factor in emergence and maintenance of multiple antimicrobial resistant pathogenic bacteria (19-21).

According to several reports, our results demonstrated that the fluoroquinolone groups such as ciprofloxacin and norfloxacin are still the most effective drugs to treat Salmonella infection (22-24). In recent years, evidence for decreasing susceptibility to fluoroquinolones in Salmonella has been reported. Increasing resistance to fluoroquinolones is growing as an issue receiving special attention, since fluoroquinolones are effective drugs against Salmonella in clinical performance and are usually considered as treatment of choice in life threatening cases (25). Our study found that Salmonella isolated from fresh vegetables were different from meat samples in both serotype distributions and antimicrobial resistance patterns. This imply that contamination in vegetable samples may originate from environmental sources that are different from animal contamination. However, this study indicated that retail meat and animals can serve as a source for MDR strains of Salmonella that may transfer to vegetables. Association or cross contamination between meat and vegetable samples is subject to further evaluations.

\section{Acknowledgements}

The authors are grateful to Ms. Chalinthorn Sinthuwattanawibool for her kindness and help in correcting language. Special thanks to all our students for their assistance in this study.

\section{Financial Disclosure}

None declared.

\section{Funding/support}

We would like to give special thanks to the Research and Development Institute, Thaksin University, for funding this study.

\section{Authors' Contribution}

None declared.

\section{References}

1. Padungtod P, Kaneene JB. Salmonella in food animals and humans in northern Thailand. Int J Food Microbiol. 2006;108(3):34654.

2. Vindigni SM, Srijan A, Wongstitwilairoong B, Marcus R, Meek J Riley PL, et al. Prevalence of foodborne microorganisms in retail foods in Thailand. Foodborne Pathog Dis. 2007;4(2):208-15.

3. Epidemiology-National Bo. Trustworthy and Competent Authority in Epidemiological Surveillance and Investigation, Annual Epidemiological Surveillance 2008 [updated 2008]; Available from: http://epid.moph.go.th/Annual/Annual\%202551/ Part1_51/Annual_MenuPart1_51.html.

4. Angkititrakul S, Chomvarin C, Chaita T, Kanistanon K, Waeth- 
ewutajarn S. Epidemiology of antimicrobial resistance in Salmonella isolated from pork, chicken meat and humans in Thailand. Southeast Asian J Trop Med Public Health. 2005;36(6):1510-5.

5. Fedorka-Cray PJ, Ladely SR, Bailey JS, Stern NJ. Colonization of broiler chicks by Salmonella typhimurium definitive phage type 104. J Food Prot. 2001;64(11):1698-704

6. Wilson IG. Antimicrobial resistance of Salmonella in raw retail chickens, imported chicken portions, and human clinical specimens. J Food Prot. 2004;67(6):1220-5.

7. Natvig EE, Ingham SC, Ingham BH, Cooperband LR, Roper TR. Salmonella enterica serovar Typhimurium and Escherichia coli contamination of root and leaf vegetables grown in soils with incorporated bovine manure. Appl Environ Microbiol. 2002;68(6):2737-44.

8. Molbak K, Gerner-Smidt P, Wegener HC. Increasing quinolone resistance in Salmonella enterica serotype Enteritidis. Emerg Infect Dis. 2002;8(5):514-5.

9. Threlfall EJ, Day M, de Pinna E, Charlett A, Goodyear KL. Assessment of factors contributing to changes in the incidence of antimicrobial drug resistance in Salmonella enterica serotypes Enteritidis and Typhimurium from humans in England and Wales in 2000, 2002 and 2004. Int J Antimicrob Agents. 2006;28(5):38995.

10. Helms M, Vastrup P, Gerner-Smidt P, Molbak K. Excess mortality associated with antimicrobial drug-resistant Salmonella typhimurium. Emerg Infect Dis. 2002;8(5):490-5.

11. Wikler MA, Clinical, Institute LS. Performance standards for antimicrobial disk susceptibility tests: approved standard. Clinical and Laboratory Standards Institute; 2006.

12. Boonmar S, Bangtrakulnonth A, Pornrunangwong S, Marnrim N, Kaneko K, Ogawa M. Salmonella in broiler chickens in Thailand with special reference to contamination of retail meat with Salmonella enteritidis. J Vet Med Sci.1998;60(11):1233-6.

13. Capita R, Alvarez-Astorga M, Alonso-Calleja C, Moreno B, del Camino Garcia-Fernandez M. Occurrence of salmonellae in retail chicken carcasses and their products in Spain. Int J Food Microbiol. 2003;81(2):169-73.

14. Pornpen P, Watcharachai N, Sasi C. Prevalence, serovars and their MIC test against antimicrobial agents of Salmonella spp.isolated from chicken and swine farms. JThai Vet Med Assoc. 2007;58(2):49-63.

15. Bangtrakulnonth A, Pornreongwong S, Pulsrikarn C, Sawanpanyalert P, Hendriksen RS, Lo Fo Wong DM, et al. Salmonella serovars from humans and other sources in Thailand, 1993-2002. Emerg
Infect Dis. 2004;10(1):131-6.

16. Aarestrup FM, Lertworapreecha M, Evans MC, Bangtrakulnonth A, Chalermchaikit T, Hendriksen RS, et al. Antimicrobial susceptibility and occurrence of resistance genes among Salmonella enterica serovar Weltevreden from different countries. J Antimicrob Chemother. 2003;52(4):715-8.

17. Lynne AM, Rhodes-Clark BS, Bliven K, Zhao S, Foley SL. Antimicrobial resistance genes associated with Salmonella enterica serovar newport isolates from food animals. Antimicrob Agents Chemother. 2008;52(1):353-6.

18. Oloya J, Doetkott D, Khaitsa ML. Antimicrobial drug resistance and molecular characterization of Salmonella isolated from domestic animals, humans, and meat products. Foodborne Pathog Dis. 2009;6(3):273-84.

19. Aarestrup FM, Kruse H, Tast E, Hammerum AM, Jensen LB. Associations between the use of antimicrobial agents for growth promotion and the occurrence of resistance among Enterococcus faecium from broilers and pigs in Denmark, Finland, and Norway. Microb Drug Resist. 2000;6(1):63-70.

20. Aarestrup FM, Wegener HC. The effects of antibiotic usage in food animals on the development of antimicrobial resistance of importance for humans in Campylobacter and Escherichia coli. Microbes Infect. 1999;1(8):639-44.

21. Vieira AR, Houe H, Wegener HC, Lo Fo Wong DM, Emborg HD. Association between tetracycline consumption and tetracycline resistance in Escherichia coli from healthy Danish slaughter pigs. Foodborne Pathog Dis. 2009;6(1):99-109.

22. Bacon RT, Sofos JN, Belk KE, Hyatt DR, Smith GC. Prevalence and antibiotic susceptibility of Salmonella isolated from beef animal hides and carcasses. J Food Prot. 2002;65(2):284-90.

23. Finley R, Reid-Smith R, Ribble C, Popa M, Vandermeer M, Aramini J. The occurrence and anti-microbial susceptibility of Salmonellae isolated from commercially available pig ear pet treats. Zoonoses Public Health. 2008;55(8-10):455-61.

24. Miranda JM, Mondragon AC, Martinez B, Guarddon M, Rodriguez JA. Prevalence and antimicrobial resistance patterns of Salmonella from different raw foods in Mexico. I Food Prot. 2009;72(5):966-71.

25. Hakanen A, Siitonen A, Kotilainen P, Huovinen P. Increasing fluoroquinolone resistance in salmonella serotypes in Finland during 1995-1997. J Antimicrob Chemother. 1999;43(1):145-8. 